BRAGA, G.M.S., ALVES, L.C. e SILVA, L.B.G. Agentes fúngicos e bacterianos numa colônia em nível laboratorial de Lutzomyia longipalpis População Imperatriz. PUBVET, Londrina, V. 5, N. 4, Ed. 151, Art. 1014, 2011.

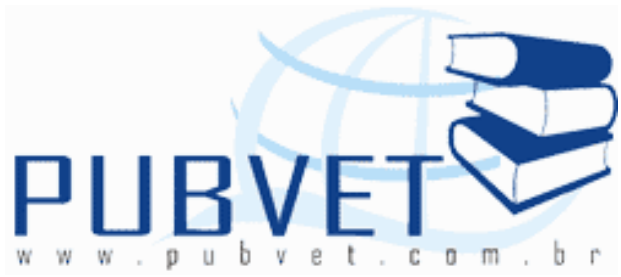

PUBVET, Publicações em Medicina Veterinária e Zootecnia.

\title{
Agentes fúngicos e bacterianos numa colônia em nível laboratorial de Lutzomyia longipalpis População Imperatriz
}
Geovania Maria da Silva Braga ${ }^{1}$; Leucio Câmara Alves²; Leonildo Bento Galiza da Silva ${ }^{3}$

${ }^{1}$ Profa Adjunta II do Curso de Biologia e Medicina Veterinária da UEMA Universidade Estadual do Maranhão, Bióloga e Médica Veterinária, Doutora em Doenças Parasitárias, PhD UNL - Universidade Nova de Lisboa.

${ }^{2}$ Prof. Titular do Curso de Pós-Graduação em Parasitologia da UFRPE Universidade Federal Rural de Pernambuco, PhD UFRRJ e Pós Doctor University of Geórgia - USA.

${ }^{3}$ Prof. Dr. do Curso de Pós-Graduação em Microbiologia da UFRPE Universidade Federal Rural de Pernambuco.

\section{Resumo}

A colonização de Lutzomyia longipalpis (Diptera: Psychodidae), vetor da Leishmaniose Visceral no Brasil foi reproduzida em laboratório. Entretanto, muito pouco se sabe sobre os contaminantes e as doenças que causam nestas colônias. O objetivo deste trabalho foi identificar a contaminação fúngica e bacteriana em colônia de Lutzomyia longipalpis. Os insetos foram coletados por armadilha CDC em diversos locais do município de Imperatriz, Estado de Maranhão, Brasil e transportado ao Laboratório de Doenças Parasitárias da UFRPE em recipientes de polietileno para colonização. A alimentação oferecida 
BRAGA, G.M.S., ALVES, L.C. e SILVA, L.B.G. Agentes fúngicos e bacterianos numa colônia em nível laboratorial de Lutzomyia longipalpis População Imperatriz. PUBVET, Londrina, V. 5, N. 4, Ed. 151, Art. 1014, 2011.

aos insetos foi de sangue de hámster e solução açucarada e estes foram mantidos em câmara aclimatizada a $27^{\circ} \mathrm{C}$ e umidade relativa de $80 \%$ para oviposição e maturação dos ovos. Diariamente, a colônia era monitorada para ver sua evolução e uma pequena quantidade de comida de peixe para larvas era polvilhada em cada recipiente. Porém, foi verificado, neste estudo, por ocasião do monitoramento das colônias de Lutzomyia longipalpis, contaminação fúngica e bacteriana. Os resultados da cultura bacteriana e fúngica mostraram Staphylococcus sp., Bacillus sp., Pseudomonas sp., Proteus sp. e Aspergillus sp. respectivamente nas colônias de Lutzomyia longipalpis. Entretanto, Staphylococcus sp. foi isolado de ovos inférteis e estágio larval, mas Aspergillus sp. e Pseudomonas sp. foram isolados somente das larvas do Lutzomyia longipalpis. Não foi observado mortalidade das pupas pela contaminação de fungos e bactérias neste estudo.

Palavras-chave: Flebotómos; Lutzomyia longipalpis; Microorganismos Patogênicos.

\title{
Fungal and bacterial agents in a colony in laboratory level of Lutzomyia longipalpis Population Empress
}

\begin{abstract}
The colonization of Lutzomyia longipalpis (Diptera: Psychodidae), vector of Visceral Leishmaniasis in Brazil, has been bred in laboratory. However, very little is known about the contaminating and the diseases they cause in these colonies. The aim of this paper was to identify the fungal and bacterial contamination in the Lutzomyia longipalpis colony. Sandflies were collected by CDC trap in locality several of studied county Imperatriz, Maranhao State, Brazil and transported to laboratory of Parasitic Diseases of the UFRPE in polystyrene containers to colonization. Blood meal from a hamster was offered to insects and solution sweet and they were kept in a acclimatized camara at $27^{\circ} \mathrm{C}$ and $80 \%$ relative humidity to oviposition and egg maturation. Everyday the colony was checked to see the evolution and a small amount of larval fish
\end{abstract}


BRAGA, G.M.S., ALVES, L.C. e SILVA, L.B.G. Agentes fúngicos e bacterianos numa colônia em nível laboratorial de Lutzomyia longipalpis População Imperatriz. PUBVET, Londrina, V. 5, N. 4, Ed. 151, Art. 1014, 2011.

chow was sprinkled in each container. However, it was examined in this study, on the occasion of the observation in the Lutzomyia longipalpis colony, the fungal and bacterial contamination was reported. The results of bacterial and fungal culture showed, Staphylococcus sp., Bacillus sp., Pseudomonas sp., Proteus sp. and Aspergillus sp. respectively on the Lutzomyia longipalpis colony. However the Staphylococus sp. was isolated from unfertilized eggs and larval stage but Aspergillus sp. and Pseudomonas sp. were isolated only from larvae of Lutzomyia longipalpis. The mortality pupae by fungal and bacterial contamination were not observed in this study.

Keywords: Phlebotomus; Lutzomyia longipalpis; Pathogenic microorganisms

\section{INTRODUÇÃO}

A necessidade de criar insetos de importância na transmissão de doenças tem sido um desafio para os entomologistas, que algumas vezes improvisam diferentes técnicas usadas em insetários (WERMELINGER e ZANUNCIO, 2001).

A colonização em laboratório é essencial para se obterem exemplares limpos de agentes etiológicos, a fim de se fazerem experiências de transmissão desses agentes, estudos sobre a biologia do díptero, bem como material para estudos morfológicos (SHERLOCK e SHERLOCK, 1959).

Contudo, a contaminação fúngica e bacteriana tem sido frequentemente observada em criação de insetos em laboratório, representando o maior obstáculo na manutenção das colônias.

Entre os artrópodes de importância médico-veterinária, os flebótomos, particularmente aqueles pertencentes ao gênero Lutzomyia, assumem importante papel em virtude de serem considerados os principais vetores das leishmanioses no Brasil (DEANE, 1956).

Colônias de Lutzomyia longipalpis têm sido estabelecidas com sucesso em diversas partes do mundo (SHERLOCK e SHERLOCK, 1959; KILLICKKENDRICK et al., 1977; READY, 1978,1979; MODI e TESH, 1983; LUITGARDSMOURA et al., 2000). 
BRAGA, G.M.S., ALVES, L.C. e SILVA, L.B.G. Agentes fúngicos e bacterianos numa colônia em nível laboratorial de Lutzomyia longipalpis População Imperatriz. PUBVET, Londrina, V. 5, N. 4, Ed. 151, Art. 1014, 2011.

Por outro lado, apesar de a dieta larval ser considerada como fator mais importante na manutenção das espécies colonizadas em laboratório, pode contribuir para proliferação de microorganismos danosos à colônia, além de às vezes, representar um complemento alimentar para espécies de flebotomíneos (WERMELINGER e ZANUNCIO, 2001) ou o insucesso na colonização destes dípteros.

O objetivo deste trabalho foi identificar os agentes fúngicos e bacterianos numa colônia em nível laboratorial de Lutzomyia longipalpis população Imperatriz.

\section{MATERIAL E MÉTODOS}

\section{Coleta dos flebótomos}

Os insetos foram coletados no Município de Imperatriz no Estado do Maranhão (50 31'35" Latitude Sul e $47^{\prime}$ 29'30" Longitude Oeste) através de armadilhas luminosas CDC (Center for Disease Control) a uma altura de 1,5 metros, nos intervalos de 18 horas às 06 horas da manhã, instaladas na mata em número de cinco, de acordo com a FIG.1, no ambiente peridomiciliar, em número de quatro, como demonstra a FIG.2, distante mais ou menos 20 metros das residências e também no intradomicílio, em número de duas (DEANE, 1956; TEODORO et al, 1993) no referido município. 
BRAGA, G.M.S., ALVES, L.C. e SILVA, L.B.G. Agentes fúngicos e bacterianos numa colônia em nível laboratorial de Lutzomyia longipalpis População Imperatriz. PUBVET, Londrina, V. 5, N. 4, Ed. 151, Art. 1014, 2011.

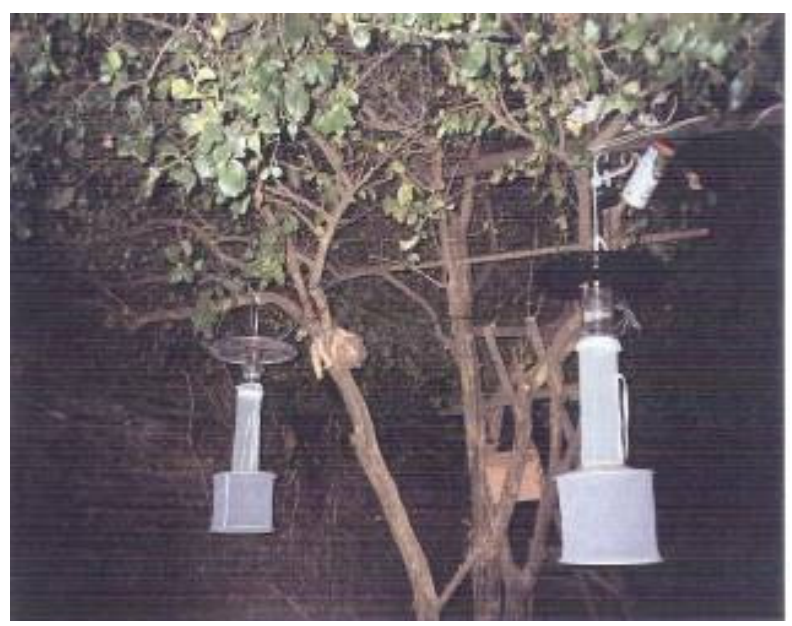

Figura 1 - Armadilhas luminosas CDC colocadas no ambiente rural para captura do inseto Lutzomyia sp. no município de Imperatriz, Maranhão, Brasil

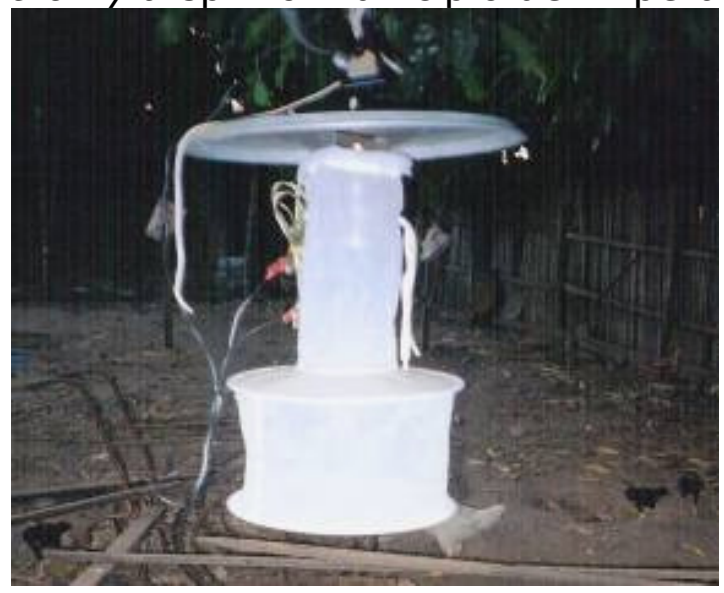

Figura 2 - Armadilhas luminosas CDC colocadas no ambiente peridomiciliar para captura do inseto Lutzomyia sp. no município de Imperatriz, Maranhão, Brasil

\section{Colonização}

Após a coleta, os flebótomos foram transferidos para o Laboratório de Endemia da Fundação Nacional de Saúde no referido município, os quais foram aspirados individualmente com o capturador de Castro (SHERLOCK e SHERLOCK 1972) e identificado de acordo com Galati (2003). Foram utilizados 
BRAGA, G.M.S., ALVES, L.C. e SILVA, L.B.G. Agentes fúngicos e bacterianos numa colônia em nível laboratorial de Lutzomyia longipalpis População Imperatriz. PUBVET, Londrina, V. 5, N. 4, Ed. 151, Art. 1014, 2011.

diversos materiais no processo de colonização dos insetos em laboratório, como visto na FIG. 3.

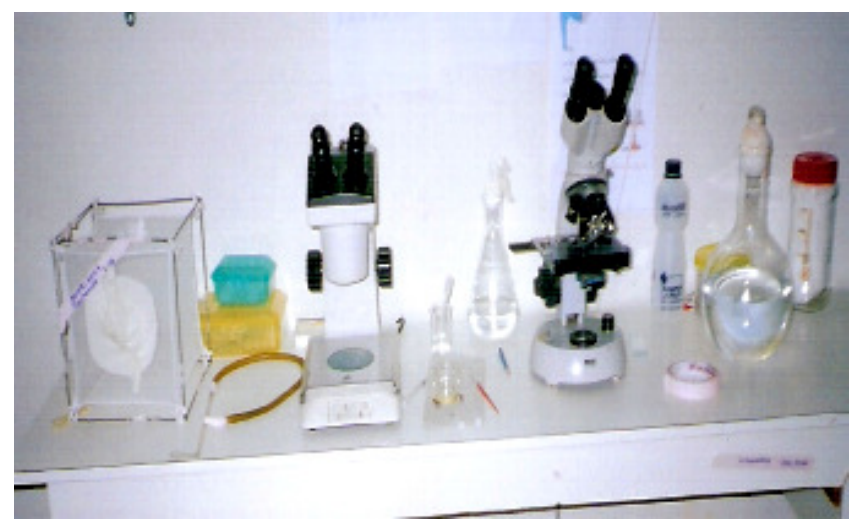

Figura 3 - Materiais utilizados no processo de colonização do inseto Lutzomyia sp.

\section{Transporte do material}

Os recipientes contendo os flebótomos coletados foram transportados para o Laboratório de Endemias da Universidade Federal do Piauí, onde foi monitorado até a oviposição e, posteriormente transportado ao Laboratório de Doenças Parasitárias dos Animais Domésticos da Universidade Federal Rural de Pernambuco, onde foram acondicionados em câmara climatizada com temperatura de $270 \mathrm{C}$ e umidade relativa de aproximadamente $80 \%$ para eclosão.

\section{Alimentação das Fêmeas}

Os exemplares fêmeas foram colocados dentro de gaiolas feitas de tecido sintético fino, medindo $20 \mathrm{~cm}$ de comprimento por $25 \mathrm{~cm}$ de altura e alimentados em hámsters, segundo Modi e Tesh (1983). As gaiolas foram acondicionadas em câmara aclimatizada com temperatura de $27^{\circ} \mathrm{C}$ e umidade relativa de $80 \%$, como evidencia a FIG. 4 . 
BRAGA, G.M.S., ALVES, L.C. e SILVA, L.B.G. Agentes fúngicos e bacterianos numa colônia em nível laboratorial de Lutzomyia longipalpis População Imperatriz. PUBVET, Londrina, V. 5, N. 4, Ed. 151, Art. 1014, 2011.

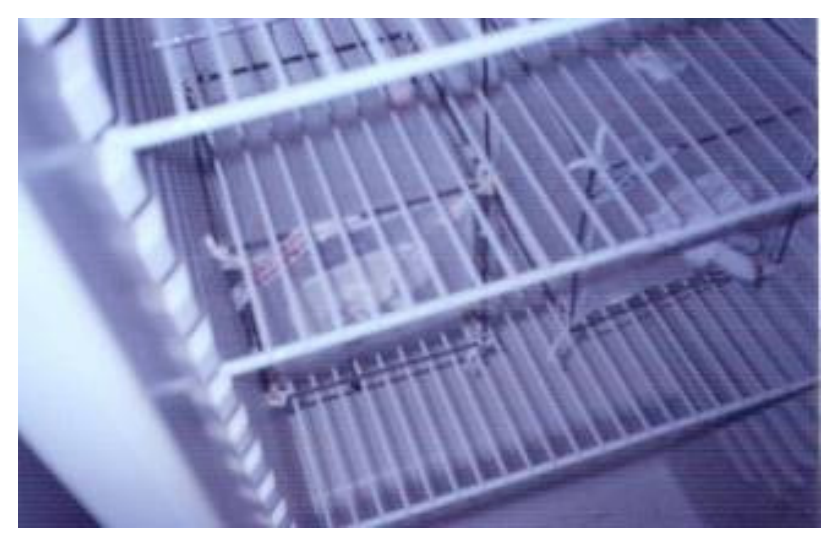

Figura 4 - Acondicionamento dos exemplares machos e fêmeas do inseto Lutzomyia sp. nas gaiolas em câmara climatizada com temperatura de $27^{\circ} \mathrm{C}$ e umidade relativa de $80 \%$ no Laboratório de Doenças Parasitárias dos Animais Domésticos da Universidade Federal Rural de Pernambuco

\section{Alimentação dos Machos}

Os exemplares machos foram alimentados com solução açucarada (READY, 1978; MODI e TESH, 1983) a base de glucose de milho ${ }^{1}$ diluídos na proporção de $30 \%$ em água destilada, embebidos em algodão e colocados à disposição dos mesmos em placa de Petri.

\section{Preparo do substrato utilizado para oviposição, larvas e pupas}

O substrato foi constituído de cristais de sulfato de cálcio hemidratado (gesso) com água destilada, que foi preparado e colocado em depósito de polietileno, com a capacidade de 300 mililitros, como explana a FIG. 5.

\footnotetext{
${ }^{1}$ Alimento a base de glucose de milho, Unilever, Bestfood Brasil Ltda.
} 
BRAGA, G.M.S., ALVES, L.C. e SILVA, L.B.G. Agentes fúngicos e bacterianos numa colônia em nível laboratorial de Lutzomyia longipalpis População Imperatriz. PUBVET, Londrina, V. 5, N. 4, Ed. 151, Art. 1014, 2011.

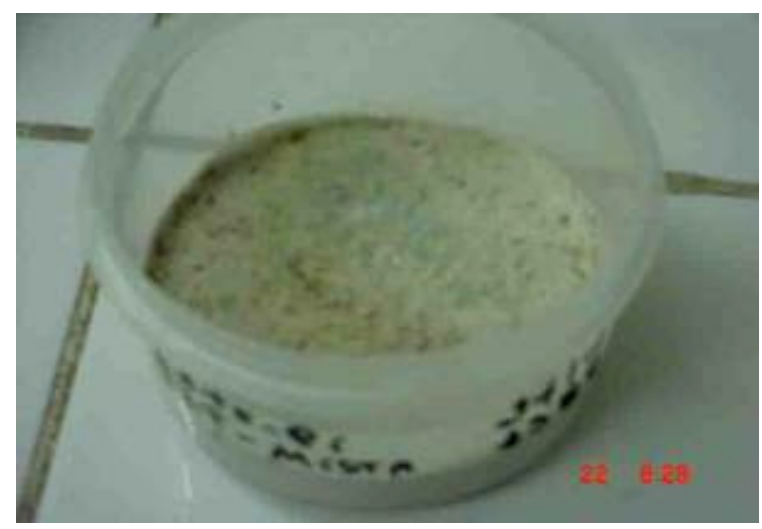

Figura 5 - Aspecto do recipiente utilizado para oviposição, larvas e pupas de Lutzomyia sp. colonizados no Laboratório de Doenças Parasitárias dos Animais Domésticos da Universidade Federal Rural de Pernambuco

Após a secagem da mistura distribuída nos recipientes em número de doze, os exemplares machos e fêmeas coletados e alimentados foram distribuídos nestas embalagens com auxilio do capturador de Castro, para realizarem a cópula. Colocou-se uma tela de tecido sintético fino, contendo uma abertura central, para facilitar a manipulação dos insetos, a qual foi vedada com um tampão de algodão, como observado na FIG. 6, para evitar a fuga dos mesmos. Diariamente foram adicionadas gotas de água destilada para manutenção da umidade nestes recipientes.

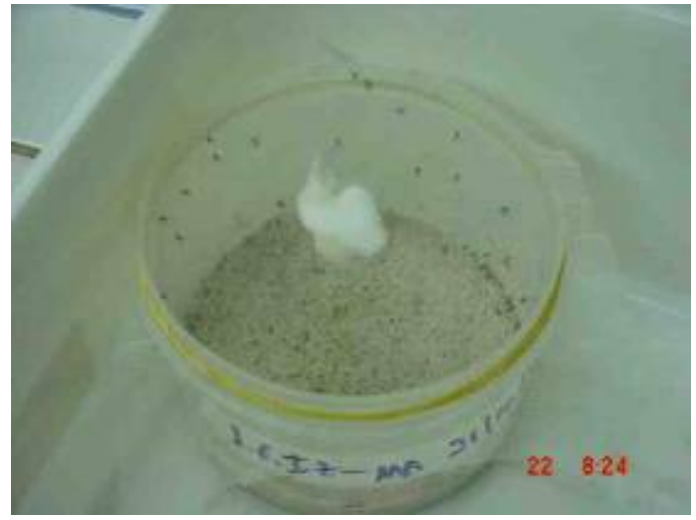

Figura 6 - Aspecto da colonização do inseto Lutzomyia sp. em recipiente com tela de tecido sintético fino, com abertura central, vedada com tampão de algodão, no Laboratório de Doenças Parasitárias dos Animais Domésticos da Universidade Federal Rural de Pernambuco 
BRAGA, G.M.S., ALVES, L.C. e SILVA, L.B.G. Agentes fúngicos e bacterianos numa colônia em nível laboratorial de Lutzomyia longipalpis População Imperatriz. PUBVET, Londrina, V. 5, N. 4, Ed. 151, Art. 1014, 2011.

\section{Alimentação das larvas}

A base da alimentação das larvas foi constituída de alimento composto para peixes, sendo liquefeitas em triturador (MODI e TESH, 1983) para posterior autoclavagem. Diariamente era adicionada aproximadamente $0,5 \mathrm{~g}$ do alimento por recipiente.

\section{Monitoramento da colônia}

Diariamente as colônias eram examinadas para visibilização do desenvolvimento dos estádios larval e pupal dos insetos, vistos na FIG. 7, além da avaliação da contaminação fúngica e bacteriana nos referidos estádios. Sendo assim, foram verificados os aspectos referentes à umidade e coloração do substrato.

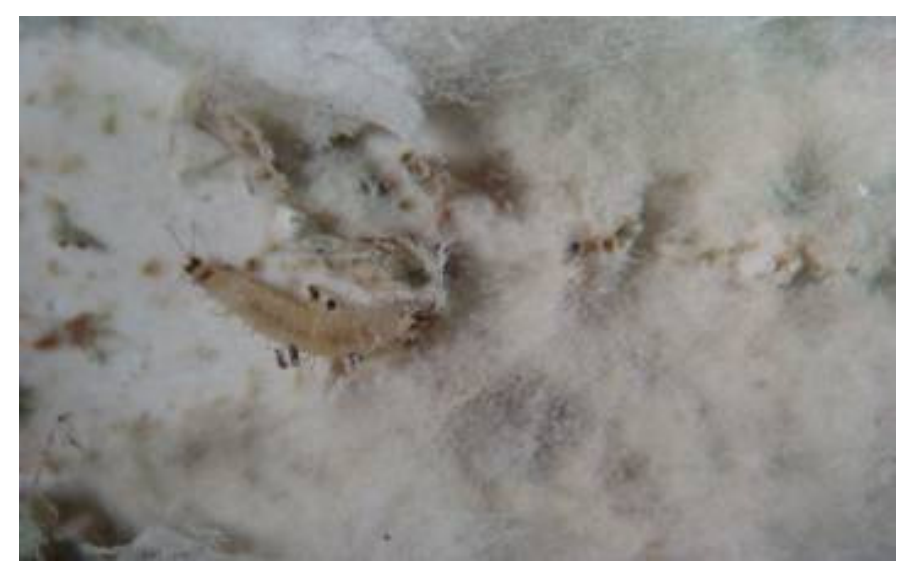

Figura 7 - Aspecto da colonização do inseto Lutzomyia sp. em estádio de larva com contaminação fúngica e bacteriana no recipiente do Laboratório de Doenças Parasitárias dos Animais Domésticos da Universidade Federal Rural de Pernambuco 
BRAGA, G.M.S., ALVES, L.C. e SILVA, L.B.G. Agentes fúngicos e bacterianos numa colônia em nível laboratorial de Lutzomyia longipalpis População Imperatriz. PUBVET, Londrina, V. 5, N. 4, Ed. 151, Art. 1014, 2011.

\section{Coleta de material das colônias}

Fragmentos do substrato, conforme FIG. 8 foram coletados e transferidos para placas de Petri, contendo Ágar Sangue ${ }^{2}$, enriquecido com $5 \%$ de sangue ovino, Agar Levine ${ }^{3}$ e Agar Sabourand ${ }^{4}$. A incubação das placas foi realizada em estufa microbiológica a $37^{\circ} \mathrm{C}$, durante 48 horas, para cultura bacteriana e para cultura fúngica as placas foram deixadas à temperatura ambiente durante 15 dias.

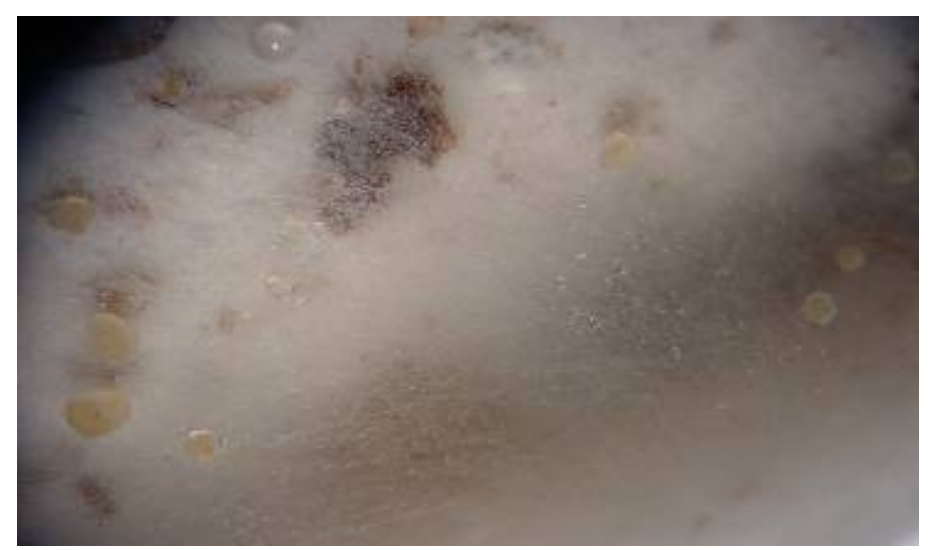

Figura 8 Substrato do recipiente da colônia do inseto Lutzomyia sp. em estádio de larva com contaminação fúngica e bacteriana no Laboratório de Doenças Parasitárias dos Animais Domésticos da Universidade Federal Rural de Pernambuco

\section{RESULTADOS E DISCUSSÃO}

Três dias após a eclosão das larvas nos recipientes foi observada modificação na coloração do substrato, o qual se apresentava de coloração amarelada e avermelhada. Os resultados da cultura bacteriana revelaram a presença de Staphylococcus sp., Bacillus sp., Pseudomonas sp., Proteus sp. e a cultura fúngica, Aspergillus sp.

\footnotetext{
${ }^{2}$ Agar Sangue, Biobrás Diagnóstico

${ }^{3}$ Agar Levine, Merck KGaA

${ }^{4}$ Agar Sabourand, Vetec Química Fina Ltda
} 
BRAGA, G.M.S., ALVES, L.C. e SILVA, L.B.G. Agentes fúngicos e bacterianos numa colônia em nível laboratorial de Lutzomyia longipalpis População Imperatriz. PUBVET, Londrina, V. 5, N. 4, Ed. 151, Art. 1014, 2011.

A avaliação da contaminação do estádio evolutivo revelou que, Staphylococus sp. foi isolado das larvas e ovos inviáveis ou seja, que não haviam eclodidos, enquanto que Aspergillus sp. e bactérias do gênero Pseudomonas sp. foram isolados apenas das larvas. Este instar de acordo com Killick-Kendrick et al. (1977) é o mais delicado e é o que representa maior perda nas colônias.

Embora Wermelinger e Zanuncio (2001), citem que a contaminação fúngica em criações de flebótomos é freqüente, os mesmos autores asseguram a importância dos fungos como complemento alimentar nas colônias.

Por outro lado, Modi e Tesh (1983) e Wermelinger e Zanuncio (2001) relatam que a contaminação fúngica é proveniente do material ofertado para alimentação das larvas. Porém, deve-se considerar no presente estudo, que o material alimentar foi autoclavado.

Sherlock e Sherlock, em 1959, já chamavam atenção para o fato de que, em criações de flebótomos podem aparecer agentes biológicos prejudiciais às colônias.

No presente estudo não foi observado mortalidade no estádio pupal. Este resultado foi diferente daqueles relatados por Luitgards-Moura et al., em 2000, que observaram contaminação e mortalidade em pupas de Lutzomyia longipalpis, porém, este resultado concorda com Killick-Kendrick et al., em 1977, quando relatam que a pupa é o mais robusto estádio e a perda é muito pequena ou mesmo nenhuma.

Outros estudos deverão ser realizados para avaliar melhor as variáveis envolvidas na colonização de flebotomíneos.

\section{CONCLUSÃO}

As contaminações bacterianas e fúngicas são fatores limitantes para a colonização de flebotomíneos. 
BRAGA, G.M.S., ALVES, L.C. e SILVA, L.B.G. Agentes fúngicos e bacterianos numa colônia em nível laboratorial de Lutzomyia longipalpis População Imperatriz. PUBVET, Londrina, V. 5, N. 4, Ed. 151, Art. 1014, 2011.

Agradecimentos: A Universidade Federal do Piauí, em nome do Dr. Carlos Henrique N. Costa e da Profa Ivete Lopes Mendonça, que muito apoiou este trabalho científico, na certeza que realmente no estudo de colônias o ciclo dos vetores flebotomíneos de cada região é diferenciado, devido às condições pluviométricas, ao clima e a umidade, sendo necessariamente o continuísmo desta pesquisa na Região Sudoeste do Estado do Maranhão.

\section{REFERÊNCIAS}

DEANE, L. M. Leishamniose Visceral no Brasil: estudos sobre reservatórios e transmissores no Estado do Ceará. Rio de Janeiro: SNES, 1956. 162 p.

GALATI, E. A. B. Morfologia e taxonomia: classificação de Phlebotominae. In RANGEL, E. F.; LAINSON, R. Flebotomíneos do Brasil. Rio de Janeiro: Fiocruz, 2003. 368 p.

KILLICK-KENDRICK R.; LEANEY A. J.; READY P. D. The establishment maintenance and productivity of a laboratory colony of Lutzomyia longipalpis (Diptera: Psychodidae). Journal of Medical Entomology, Lanham, v. 13, n. 4/5, p. 429-440, 1977.

LUITGARDS-MOURA, J. F.; CASTELLON BERMUDEZ, E. G.; ROSA-FREITAS, M. G. Aspects related to productivity for four generations of a Lutzomyia longipalpis laboratory colony. Memórias Instituto Oswaldo Cruz, Rio de Janeiro, v. 95, n. 2, p. 251-257, 2000.

MODI, G. B.; TESH, R. B. A simple technique for mass rearing Lutzomyia longipalpis and Phlebotomus papatasi (Diptera: Psychodidae) in the laboratory. Journal of Medical Entomology, Lanham, v. 20, n. 5, p. 568-569, 1983.

READY, P. D. The feeding habits of laboratory-bred Lutzomyia longipalpis (Diptera, Psychodidae). Journal of Medical Entomology, Lanham, v. 14, n. 5, p. 545-552, 1978.

READY, P. D. Factors affecting egg production of laboratory bred Lutzomyia longipalpis (Diptera: Psychodidae). Journal of Medical Entomology, Lanham, v. 16, n.5, p. 413-423, 1979.

SHERLOCK, I. A.; SHERLOCK, V.A. Criação e biologia em laboratório, do "Phlebotomus longipalpis" Lutz \& Neiva, 1912 (Diptera Psychodidae). Revista Brasileira Biologia, Rio de Janeiro, v. 19, n. 3, p. 229-250, 1959.

SHERLOCK, I. A.; SHERLOCK, V.A. Métodos práticos para criação de flebotomíneos em laboratório. Revista Brasileira Biologia, Rio de Janeiro, v. 32, n. 2, p. 209-217, 1972.

TEODORO, V. et al. Flebotomíneos em área de transmissão de LT na região norte do estado do Paraná-Brasil: variação sazonal e atividade noturna. Revista Saúde Pública, São Paulo, v. 27, p. 190-194, 1993.

WERMELING, E. D.; ZANUNCIO, J. C. Development of Lutzomyia intermedia and Lutzomyia longipalpis (Diptera: Psychodidae: Phlebotominae) larvae in different diets. Brazilian Journal Biology, São Carlos, v. 61, n. 3, p. 405-408, 2001. 